\title{
FROM WASHINGTON
}

\section{DOE Notes}

\section{DMS Contractors Meeting on Radiation Effects}

The Division of Materials Sciences (DMS) of DOE's Office of Basic Energy Sciences (BES) funds research on the effects of radiation on materials at several laboratories around the United States. The term "radiation effects," explicitly intended to encompass more than just radiation damage per se, includes all types of material property and microstructure modification and degradation. Because the field is so broad, a contractors meeting was arranged so that researchers supported by BESIDMS could compare the status and directions of their programs and benefit from an overview of the program's focus.

Don M. Parkin of Los Alamos National Laboratory (LANL) arranged the meeting held on August 5 and 6, 1986 at the Center for Materials Science at LANL. Assisting with the program was Donald W. Keefer of BES/DMS. After Parkin's introductory remarks, Frank V. Nolfi, Jr. gave his and DMS's view of the state and scope of the funded research. Presentations were made by L.E. Rehn (Argonne National Laboratory), L.K. Mansur (Oak Ridge National Laboratory-Metals and Ceramics Division), S.T. Picraux (Sandia National LaboratoryAlbuquerque), J.B. Roberto (Oak Ridge National Laboratory-Solid State Division), R.H. Kerchner (Oak Ridge National Laboratory-Low Temperature Neutron Irradiation Facility), F.W. Clinard (Los Alamos National Laboratory), E.N. Kaufmann (Lawrence Livermore National Labora-

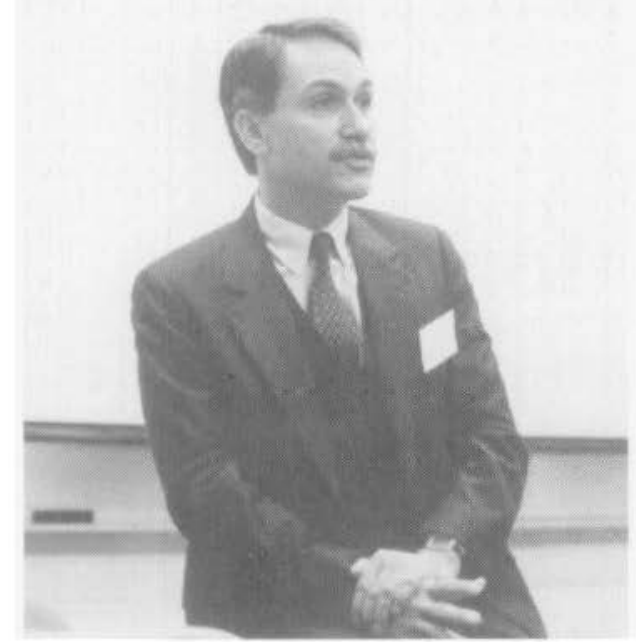

Frank V. Nolfi

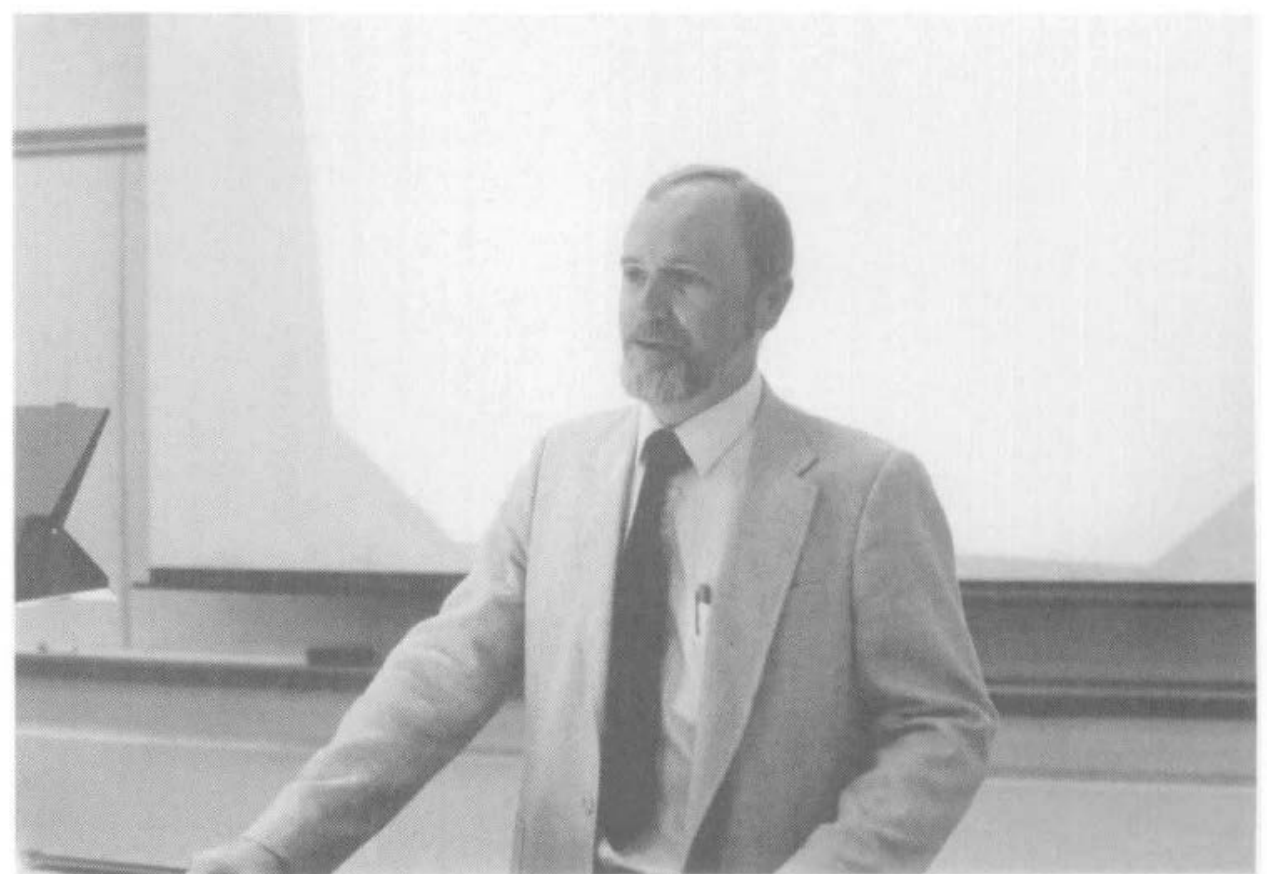

Don M. Parkin

tory), L.W. Hobbs (MIT), S.S. Lau (University of California-San Diego), B. Chakoumakos (University of New Mexico), T. C. Reuther (DOE), and M. Guinan (Lawrence Livermore National Laboratory).

On the second day, panel and group discussions covered phase microstructure, ion beam materials interactions, defects in concentrated alloys, nonequilibrium states of condensed matter, and radiation effects in ceramics. Additional presenters included R. Averback (Argonne National Labora- tory), W. Wolfer (Sandia National Laboratory-Livermore), and $W$. Johnson (Caltech). It is expected that such gatherings will be repeated as one means of informally insuring that laboratories pursuing studies in the same general area supported by DMS stay in touch with the results and directions of their colleagues.

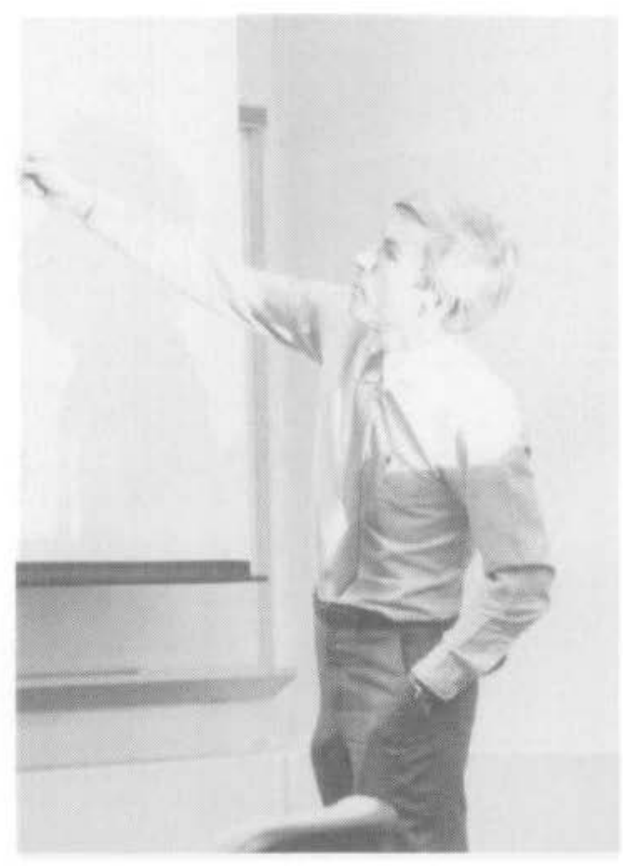

S. Tom Picraux

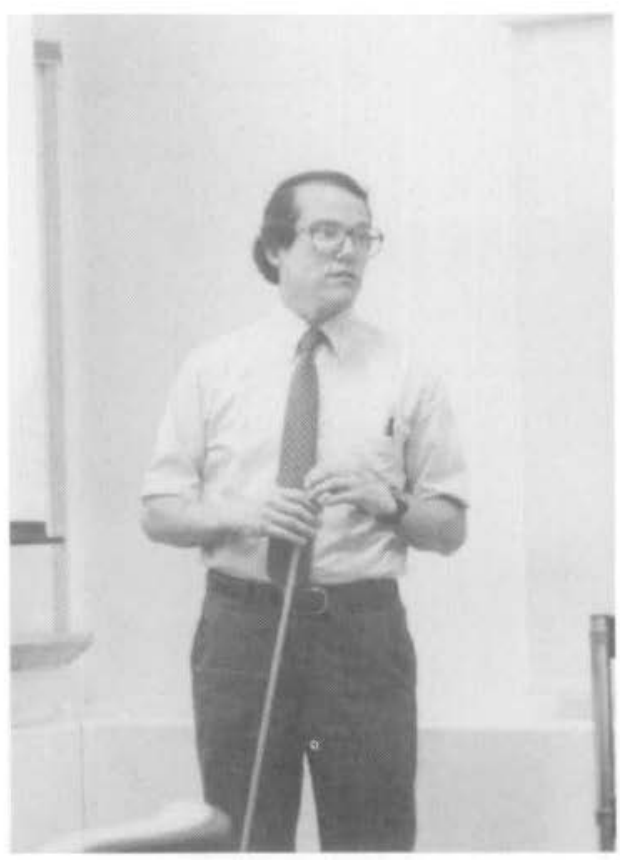

Jim Roberto 